\title{
Magnetite-catalyzed selenium reduction
}

\author{
AGNIESZKA POULAIN ${ }^{1}$, SARA GOBERNA FERRON ${ }^{2}$, \\ LAURENT CHARLET ${ }^{3}$ AND ALEJANDRO FERNANDEZ- \\ MARTINEZ ${ }^{4}$
}

${ }^{1}$ ISTerre, CNRS \& Univ. Grenoble Alpes

${ }^{2}$ ISTerre : Institut des Sciences de la Terre

${ }^{3}$ ISTerre, CNRS

${ }^{4}$ ISTerre, Univ. Grenoble-Alpes, CNRS

Presenting Author: agnieszka.poulain@univ-grenoble-alpes.fr

Magnetite nanoparticles are widespread mixed-valence iron oxides of industrial and environmental relevance. Among other occurrences, they form during canister steel corrosion in the context of nuclear waste disposal initiatives. Their reactivity towards radionuclides -such as ${ }^{79} \mathrm{Se}$ - is therefore an imporant area of research. Here we present a study of the redox reactivity of magnetite nanoparticles towards $\mathrm{Se}(\mathrm{VI})$ oxyanions -selenate, evaluating the ability of electrons to be transferred through nonconducting interfacial silica layers. Moreover, the competition for adsorption sites between selenate, silicate and rhenate is also evaluated. Results from potentiometric titration, adsorption isotherms, FTIR spectroscopy and X-ray absorption spectroscopy show that electron transfer is still occurring through thin silica layers, with transfer rates greatly decreased. The reduction of $\mathrm{Se}(\mathrm{VI})$ to Se(IV) occurs with initial fast electron exchange at the surface of magnetite which brings first reduction of $\mathrm{Se}(\mathrm{VI})$ to $\mathrm{Se}(\mathrm{IV})$, and then instantaneous conversion to $\mathrm{Se}(0)$ - the most stable insoluble form. A competition between silicate and the sorbed $\mathrm{Se}(\mathrm{VI})$ and $\mathrm{Se}(\mathrm{IV})$ is described. We conclude that neither partial oxidation nor silica surface coatings block the sorption and redox-catalytic properties of magnetite nanoparticles, a result with important implications to assess the reactivity of mixedvalence phases in environmental settings. 